\title{
Keratinocyte Gene Therapy for Systemic Diseases \\ Circulating Interleukin 10 Released from Gene-transferred Keratinocytes Inhibits Contact Hypersensitivity at Distant Areas of the Skin
}

\author{
Xianmin Meng, Daisuke Sawamura, Katsuto Tamai, Katsumi Hanada, Hiroshi Ishida, ${ }^{\star}$ and Isao Hashimoto \\ Department of Dermatology, Hirosaki University School of Medicine, Hirosaki 036, Japan; and *Department of Internal Medicine, \\ Clinical Research Center, National Utano Hospital, Kyoto 616, Japan
}

\begin{abstract}
This study has examined the systemic effects of a circulating gene product, human interleukin 10 (IL-10), released from transduced keratinocytes. IL-10 is an anti-inflammatory cytokine which has an inhibitory effect on contact hypersensitivity (CHS). An expression vector (phIL-10) was constructed for human IL-10 and was injected into the dorsal skin of hairless rats. Local expression of IL-10 mRNA and protein was detected by reverse-transcriptase polymerase chain reaction and immunohistochemical staining, respectively. Enzyme-linked immunosorbent assay showed that the amount of IL-10 in the local keratinocytes and in the circulation increased with the dose of phIL-10 transferred. To determine whether circulating IL-10 could inhibit the effector phase of CHS at a distant area of the skin, various doses of phIL-10 were injected into the dorsal skin of sensitized rats before challenge on the ears. Our results showed that the degree of swelling of the ears of phIL-10treated rats was significantly lower than that in the negative control animals. These results suggest that IL-10 released from transduced keratinocytes can enter the bloodstream and cause biological effects at distant areas of the skin. This study demonstrates that it may be possible to treat systemic disease using keratinocyte gene therapy. (J. Clin. Invest. 1998. 101:1462-1467.) Key words: cytokine $\cdot$ bioreactor $•$ gene expression • epidermis • dermatitis
\end{abstract}

\section{Introduction}

Gene therapy has received much attention over the past few years as a novel method for treating inherited and acquired diseases, and keratinocytes have been demonstrated to be suitable target cells for gene therapy by several research groups $(1,2)$. Keratinocyte gene therapy may be appropriate for treating diseases caused by genetic defects which result in keratinocytes with abnormal proteins. Keratinocytes are relatively easy to obtain and can easily be monitored for the expression of transgenes. Keratinocytes can be used as bioreactors releas-

Address correspondence to Xianmin Meng, M.D., Dept. of Dermatology, Hirosaki University School of Medicine, 5 Zaifu-cho, Hirosaki 036, Japan. Phone: 81-172-39-5087; FAX: 81-172-37-6060; E-mail: mengderm@cc.hirosaki-u.ac.jp

Received for publication 25 June 1997 and accepted in revised form 21 January 1998.

J. Clin. Invest.

(C) The American Society for Clinical Investigation, Inc. 0021-9738/98/03/1462/06 \$2.00

Volume 101, Number 6, March 1998, 1462-1467

http://www.jci.org ing the transgenic protein into the circulation, and the endocrine and systemic effects of the protein required for therapy can be monitored $(2,3)$.

In keratinocyte gene therapy, the first problem is how to introduce an exogenous gene. Using various techniques including chemical physical, and biological methods, the introduction and local expression of foreign genes have been accomplished in keratinocytes (1-3). The expressed proteins have been detected in the circulation after both in vivo (4-7) and ex vivo (7-10) gene transfer methods, although the biological effects of these proteins on distant cells or organs have not yet been demonstrated.

The DNA-plasmid injection method was first used to introduce foreign genes into mouse muscle $(11,12)$. Recently, the introduction and local expression of foreign genes have also been achieved in vivo in keratinocytes using this method (13, 14). DNA-plasmid injection is a relatively easy and efficient way to perform gene transfer. If it results in a high enough concentration of the transgenic protein in the circulation to have biological effects, keratinocyte gene therapy will be regarded as a potential method for treating systemic diseases.

IL-10 is known to play a major role in suppressing immune and inflammatory responses by inhibiting the production of proinflammatory cytokines (15). Recent studies have shown that local application or intraperitoneal injection of recombinant IL-10 (rIL-10) ${ }^{1}$ suppresses the effector phase of contact hypersensitivity (CHS) (15-18). Therefore, an animal model of CHS was chosen in this study to examine the biological effects of circulating IL-10 released from gene-transferred keratinocytes.

A human IL-10 expression vector was constructed and transduced into rat skin using the naked DNA method. Specific mRNA and IL-10 expression were observed in epidermal keratinocytes in the treated area and circulating IL-10 was also detected in the bloodstream. Circulating IL-10 released from treated keratinocytes was shown to suppress the effector phase of CHS at a distant area of the skin. This study is the first to show that it may be possible to treat diseases using circulating gene products released from transduced keratinocytes by naked DNA injection method.

\section{Methods}

Animals. Hirosaki hairless rats (HHR), weighing 180-200 g, were used in this study since it has been shown previously that HHR could develop CHS to dinitrochlorobenzene (DNCB) (19) and that the $\beta$-galactosidase ( $\beta$-Gal) gene could be transferred to keratinocytes of

1. Abbreviations used in this paper: $\beta$-Gal, $\beta$-galactosidase; $\mathrm{CHS}$, contact hypersensitivity; DNCB, dinitrochlorobenzene; HHR, Hirosaki hairless rat; phIL-10, human IL-10 plasmid; rIL-10, recombinant IL-10; $\mathrm{RT}$, reverse transcriptase. 
HHR using the DNA-plasmid injection method (20). Six or seven female rats, 10-12 wk of age, were selected randomly for each group.

Construction of human $I L-10$ expression vector. To amplify the 534-bp coding region of human IL-10 cDNA using PCR, two primers, 5'-GGAAGCTTGAAGGCATGCACAGCTCAGCACTG-3' and 5'- GGGAATTCTCAGTTTCGTATCTTCATTGT-3', were synthesized based on the cDNA sequence of human IL-10 (21). For subcloning, the primers contained restriction enzyme sites for HindIII and EcoRI at the $5^{\prime}$ and $3^{\prime}$-ends, respectively. PCR was performed with oligo-dT-primed lymphocyte cDNA as a template. After sequence analysis of the 534-bp DNA fragment, it was digested with HindIII and EcoRI, and subcloned into a pCY4B expression vector which contained a chicken $\beta$-actin promoter with a cytomegalovirus immediate early enhancer and a 3 '-flanking sequence from the rabbit $\beta$-globin gene. This expression vector was designated phIL-10. A plasmid [phIL-10(-)] containing the IL-10 cDNA without any eukaryotic promoter was used as a negative control.

In vivo DNA transfer to keratinocytes. The DNA plasmid, phIL10 , was injected into the dorsal skin of $\operatorname{HHR}(13,20)$. All rats were anesthetized with $1 \mathrm{ml} \mathrm{3.6 \%}$ chloralhydrate per $100 \mathrm{~g}$ of body wt. Plasmid DNA was diluted in PBS to various concentrations. Injection of DNA into the rats was performed with a $29 \mathrm{G}$ needle. The injected volume was 30-50 $\mu \mathrm{l}$ per injection site and the concentration of DNA ranged from 0.01 to $2.0 \mu \mathrm{g} / \mu \mathrm{l}$. Skin biopsies were taken from the injection sites at various times after injection.

Reverse-transcriptase (RT)-PCR for IL-10 gene expression. Either phIL-10 or phIL-10(-), at a concentration of $0.2 \mu \mathrm{g} / \mu \mathrm{l}$, was injected into a $2 \times 2 \mathrm{~cm}$ area of the dorsal skin of the HHR and biopsies were taken from the injected sites $24 \mathrm{~h}$ later. Skin sheets were incubated for $3 \mathrm{~h}$ at $37^{\circ} \mathrm{C}$ with $1,000 \mathrm{pU} / \mathrm{ml}$ dispase (GoDo Shusei Co. Ltd., Tokyo, Japan) to split the epidermis from the dermis. All of the RNA from the keratinocytes was extracted from the epidermal sheet using a RNeasy total RNA kit (QIAGEN Inc., Chatsworth, CA). To remove contaminating plasmid DNA, the RNA sample was incubated with 50 $\mathrm{U} / \mathrm{ml}$ RNase-free DNase for $2 \mathrm{~h}$ at $37^{\circ} \mathrm{C}$ (13), followed by phenol/chloroform extraction and ethanol precipitation. Oligo-dT-primed keratinocyte cDNA was synthesized using a cDNA synthesis kit (CLONTECH, Palo Alto, CA), and PCR was performed as described above. PCR products were analyzed by $2 \%$ agarose gel electrophoresis.

Immunohistochemical staining. Skin biopsy specimens were taken from the sites injected with phIL-10. The specimens were fixed, paraffin-embedded, and 5- $\mu \mathrm{m}$ sections were cut. A polyclonal antihuman IL-10 antibody (goat IgG) (22) was used in a concentration of $5 \mu \mathrm{g} / \mathrm{ml}$. Control staining was done suing an isotype antibody, goat anti-human $\operatorname{IgG}(\mathrm{H}+\mathrm{L})$ (Jackson ImmunoResearch Laboratories, West Grove, PA).

ELISA for IL-10 in keratinocytes. phIL-10, in a series concentration from 0.01 to $2.0 \mu \mathrm{g} / \mu \mathrm{l}$ (injection volume, $200 \mu \mathrm{l}$ ), was injected into a $2 \times 2 \mathrm{~cm}$ area of the dorsal skin of HHR. rIL-10, at doses of 10 and $100 \mathrm{ng}$, was used as a positive control and phIL-10(-) in $0.2 \mu \mathrm{g} / \mu \mathrm{l}$ was used as negative control. The injection areas were excised $24 \mathrm{~h}$ after injection by 6-mm punch biopsy and treated with dispase as described above. The epidermal sheets of biopsy samples were treated with $0.25 \%$ trypsin for $30 \mathrm{~min}$ at $37^{\circ} \mathrm{C}$ to obtain single cell suspensions. The keratinocytes were suspended in $0.1 \mathrm{M}$ Tris ( $\mathrm{pH} 7.0)$, lysed by three cycles of freeze-thawing, and centrifuged at 5,000 rpm. The concentration of IL-10 in the supernatant was measured with a Cytoscreen $^{\mathrm{TM}}$ US hIL-10 ELISA kit (BioSource International, Inc., Camarillo, CA) and was expressed as nanograms per microgram of protein (protein assay kit; Bio-Rad, Hercules, CA). In terms of the specificity, we examined the same samples used in human IL-10 ELISA with the rat IL-10 immunoassay kit (BioSource International, Inc.) which is specific for rat IL-10 and has no cross-reactivity with human IL-10.

ELISA for IL-10 in serum. Rats were divided into groups according to the dose of phIL-10 injected, either 80,120 , or $160 \mu \mathrm{g}$. phIL-10 was injected into the dorsal skin of HHR at a concentration of $0.2 \mu \mathrm{g} / \mu \mathrm{l}$. phIL-10(-) $(160 \mu \mathrm{g})$ was injected into the control group of animals. Serum IL-10 concentrations were determined by ELISA at various times after injection. Briefly, whole blood samples were taken and collected with a blood collecting tube at various times after DNA injection and centrifuged immediately at 5,000 rpm for $5 \mathrm{~min}$ at $4^{\circ} \mathrm{C}$ to remove blood cells. Serum samples were stored at $-70^{\circ} \mathrm{C}$ for ELISA. Rat IL-10 ELISA was also performed with the same serum samples.

Contact hypersensitivity. HHR were sensitized by painting $100 \mu \mathrm{l}$ of $2.5 \%$ DNCB dissolved in acetone/olive oil (4:1) vehicle on the abdominal skin. Challenge was performed by applying $20 \mu \mathrm{l}$ of $1 \%$ DNCB on both sides of the ears $5 \mathrm{~d}$ after the sensitization. phIL-10 was injected into the dorsal skin at various doses $12 \mathrm{~h}$ before challenge. The degree of CHS was determined by measuring the change in thickness of the ear due to swelling. Ear thickness was measured at various times after challenge with a dial thickness gauge. The percent increase in ear thickness was calculated using the following formula to indicate the degree of swelling: Ear swelling $=$ (ear thickness after challenge - ear thickness before challenge)/ear thickness before challenge $\times 100$.

Statistical analysis of data. Significant differences between groups were evaluated using the Student's $t$ test.

\section{Results}

Human IL-10 mRNA expression in rat keratinocytes. To determine whether keratinocytes could express human IL-10 mRNA after introduction of phIL-10, RT-PCR was performed using RNA samples from keratinocytes. RNA samples were first treated with DNase to avoid amplification of phIL-10 itself. Fig. 1 shows that a 534-bp band was present in the sample from phIL-10-transferred keratinocytes, whereas no band was observed in the RNA sample from phIL-10(-)-transferred keratinocytes. PCR with mRNA samples without an RT step were also performed and no hIL-10 DNA band was detected (data not shown).

Detection of human IL-10 in rat keratinocytes. To confirm that the transduced keratinocytes expressed IL-10, we examined the skin at the site of injection by immunohistochemical staining. Skin biopsy specimens were taken from the injection site $24 \mathrm{~h}$ after introduction of phIL-10. Positive immunoreactivities for IL-10 were clearly recognized in the cytoplasm of epidermal keratinocytes. Although positive staining of keratinocytes can be seen from suprabasal to upper level keratinocytes, the basal cells are almost negative (Fig. $2 a$ ). The results of Hengge (13) and Sawamura (20) showed that, after

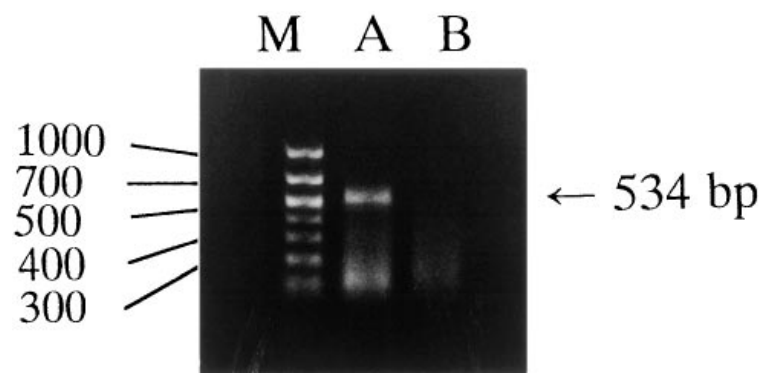

Figure 1. Detection of human IL-10 mRNA expression in keratinocytes after phIL-10 transfer by RT-PCR. Total RNA was extracted from keratinocytes from gene-transferred areas $24 \mathrm{~h}$ after phIL-10 or phIL-10(-) injection and RT-PCR was performed using primers to amplify IL-10 cDNA. $A$, phIL-10 injection; $B$, phIL-10(-) injection; $M$, size marker. 

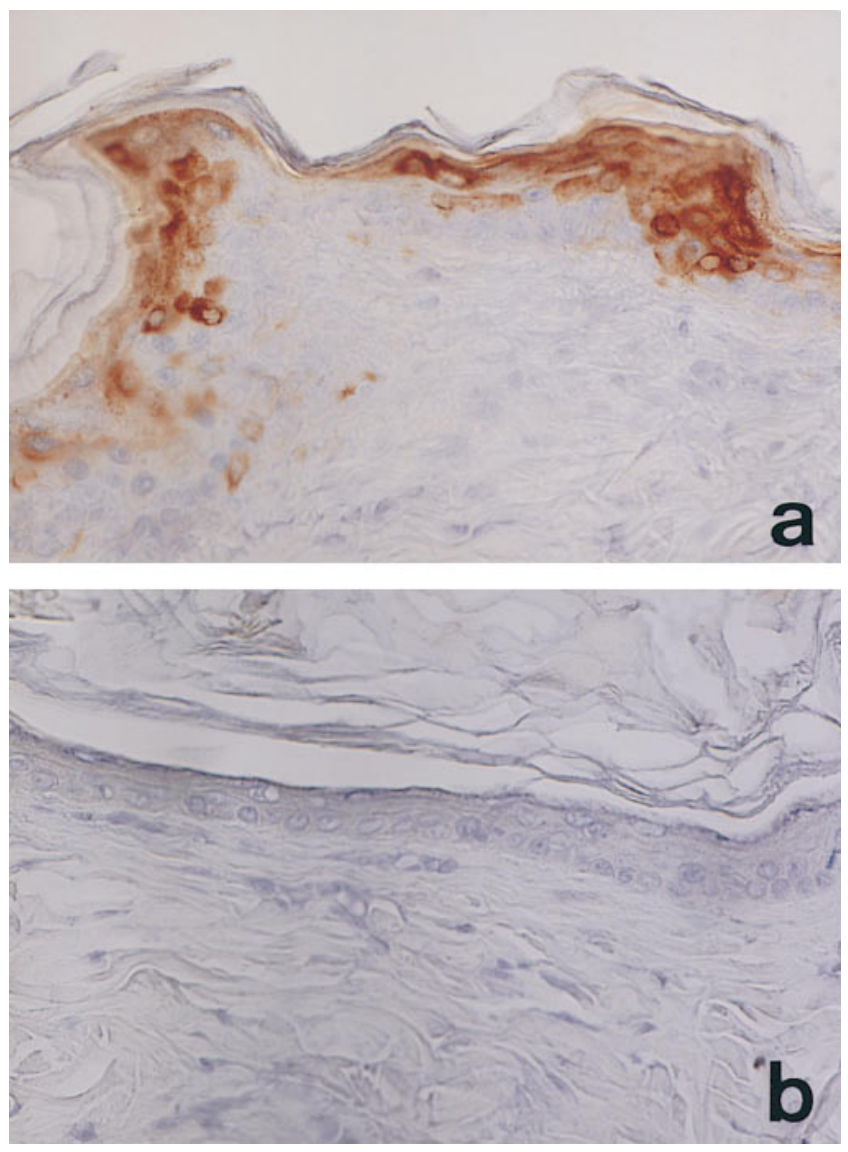

Figure 2. Immunohistochemical staining demonstrating human IL-10 in keratinocytes after phIL-10 transfer. Skin specimens were taken from gene-transferred areas $24 \mathrm{~h}$ after phIL-10 injection and incubated with an anti-human IL-10 polyclonal antibody. IL-10 positive staining was clearly recognized in the cytoplasm of epidermal keratinocytes $(a)$. An isotype antibody, goat anti-human $\operatorname{IgG}(\mathrm{H}+\mathrm{L})$ was also used for staining, but no positive staining was observed $(b)$.

subcutaneous injection of $\beta$-Gal expression vector, $\beta$-Gal positive staining was seen in the epidermis in a similar pattern with our staining result. This may be due to the fact that, for unclear reasons, in this stage, the gene transferring rate is still low and transgene cannot be expressed by every layer of the epidermis and every single keratinocyte with the naked DNA method. We also performed control staining using an isotype antibody, goat anti-human $\mathrm{IgG}(\mathrm{H}+\mathrm{L})$, and no positive staining was observed (Fig. $2 b$ ). There were no abnormal histological changes observed in either the treated or untreated specimens (data not shown). This result indicates that human IL-10 was synthesized by keratinocytes in phIL-10-treated skin.

The relationship between the concentration of PIL-10 and transgenic $I L-10$. To determine the optimal DNA concentration for the transgene expression, we injected various concentrations of pIL-10 and performed ELISA for human IL-10 (Fig. 3). The amount of IL-10 produced was increased with the concentration of phIL-10 injected until $0.2 \mu \mathrm{g} / \mu \mathrm{l}$. When this concentration was $>0.5 \mu \mathrm{g} / \mu \mathrm{l}$, the amounts of transgenic IL-10 become even lower than that of the $0.2 \mu \mathrm{g} / \mu \mathrm{l}$ concentration. This result is similar to those in previous reports about $\beta$-Gal ex- pression in keratinocytes after injection of $\beta$-Gal expression vector (13). So, from these results, we thought that the optimal plasmid DNA concentration was $0.2-0.5 \mu \mathrm{g} / \mu \mathrm{l}$ in case of transferring plasmid DNA into keratinocyte with the naked DNA injection method. For this reason, we used the concentration of $0.2 \mu \mathrm{g} / \mu \mathrm{l}$ in our later experiments. On the other hand, keratinocytes in rIL-10-injected sites showed very low IL-10 level $24 \mathrm{~h}$ after rIL-10 injection. However, transgenic IL-10 levels then decreased and disappeared totally after $7 \mathrm{~d}$ (data not shown). Our results of rat IL-10 ELISA showed that, after injection of pIL-10 or pIL-10(-), rat IL-10 could be detected as $0.32 \mathrm{pg} / \mathrm{\mu g}$ $(n=6)$ in epidermal keratinocyte samples. This amount is obviously lower than the hIL-10 amounts.

Human IL-10 in serum after introduction of phIL-10 into keratinocytes. The amount of human IL-10 in serum was measured to determine whether transgenic human IL-10 could be secreted into the circulation. Serum IL-10 levels were assayed at various times after injection of different doses of phIL-10 $(80,120$, and $160 \mu \mathrm{g})$. ELISA detected a significant amount of human IL-10 in the sera from all treated groups and the amount detected was seen to increase with the dose of phIL-10 injected. The level of IL-10 in the bloodstream began to increase $3 \mathrm{~h}$ after injection and then increased rapidly to reach a maximum level at $18 \mathrm{~h}$. Serum IL-10 then decreased gradually (Fig. 4). IL-10 could be detected $6 \mathrm{~d}$ after a single injection of $120 \mu \mathrm{g}$ phIL-10. Serum IL-10 was not detected after injection of the rats with PBS or phIL-10(-) (data not shown). After intraperitoneal injection with rIL-10, serum IL-10 increased rapidly to a high level and then decreased rapidly and had almost disappeared $12 \mathrm{~h}$ after injection (data not shown). The rat IL10 was undetectable in all serum samples.

Inhibition of the effector phase of CHS by phIL-10 transfer. To determine whether transgenic human IL-10 released from transduced keratinocytes could have a suppressive effect on CHS at a distant area of the skin, phIL-10 was injected $12 \mathrm{~h}$

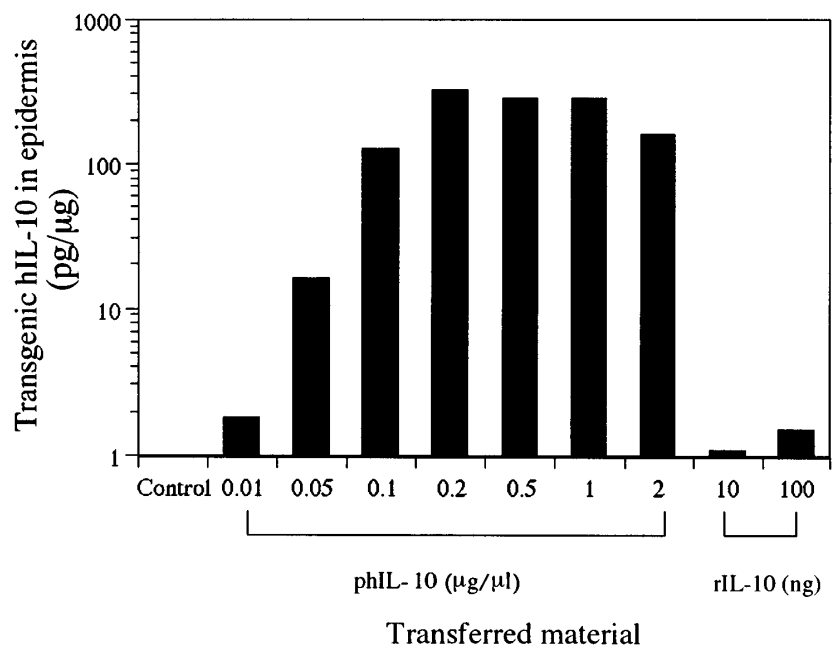

Figure 3. ELISA results demonstrating human IL-10 in keratinocytes after phIL-10 transfer. Keratinocytes were prepared from gene-transferred areas $24 \mathrm{~h}$ after injection of various concentrations of phIL-10, and 10 or $100 \mathrm{ng}$ of rIL-10. The IL-10 levels were assayed by ELISA. Each value shown represents the mean of six individual samples. Experiments were repeated at least three times; results show one representative experiment. 


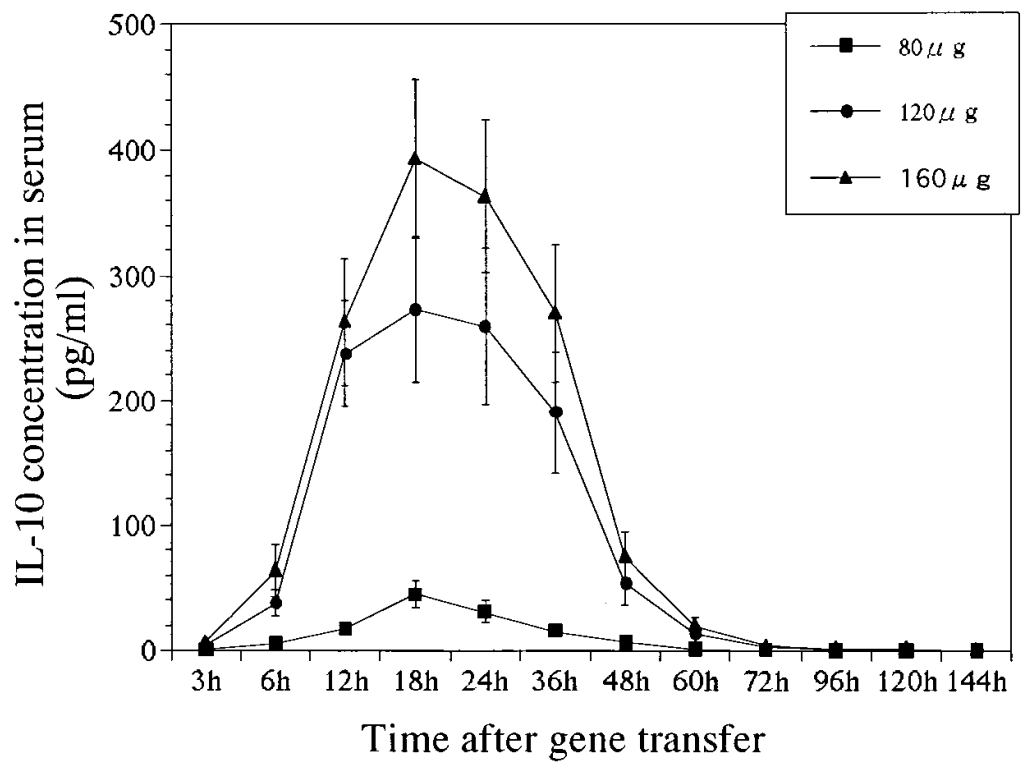

Figure 4. ELISA results demonstrating human IL-10 in serum after phIL-10 transfer. Rat serum samples were taken at various times after injection of 80,120 , or 160 $\mu \mathrm{g}$ phIL-10 and the IL-10 level was assayed by ELISA. Each value shown represents the mean \pm SEM of six individual samples. Experiments were repeated at least three times; results show one representative experiment. before challenge and ear swelling was measured $24 \mathrm{~h}$ after challenge with DNCB. As shown in Fig. 5, the degree of ear swelling in the 120 and $160 \mu$ groups was significantly lower than that in the phIL-10(-) group. There was no significant difference between the $80 \mu \mathrm{g}$ and negative control groups. As a positive control, intraperitoneal administration of $5 \mu \mathrm{g}$ rIL-10 also inhibited CHS. Our results demonstrate that the effector phase of CHS was inhibited by introduction of the human IL-10 gene.

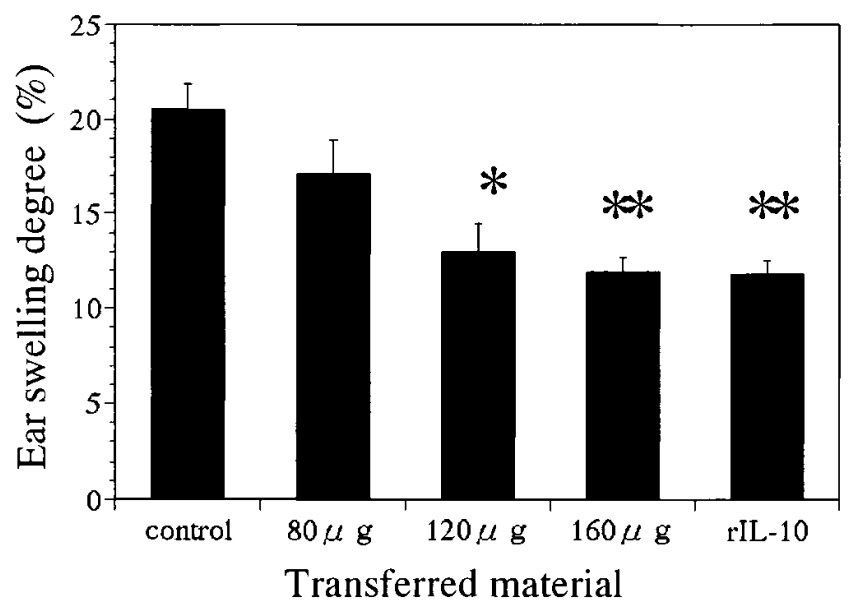

Figure 5. Inhibition of the effector phase of CHS by phIL-10 transfer. phIL-10, at doses of 80,120, and $160 \mu \mathrm{g}$, was injected into DNCBsensitized rats $12 \mathrm{~h}$ before challenge and ear swelling was measured $24 \mathrm{~h}$ after challenge with DNCB. rIL-10 at a dose of $5 \mu \mathrm{g}$ and phIL-10(-) at a dose of $160 \mu \mathrm{g}$ were used as positive and negative controls, respectively. Each value represents the mean \pm SEM of seven individual samples. Experiments were repeated at least three times; results show one representative experiment. The 120 and $160 \mu \mathrm{g}$ groups and rIL-10 groups were significantly different from phIL-10(-) (control), $* P<0.05, * * P<0.01$.

\section{Discussion}

Several different methods for in vivo gene transfer to keratinocytes have been proposed by several research groups. Cheng et al. (23) and Setoguchi et al. (7) succeeded in transferring genes to keratinocytes using particle bombardment and replication-deficient recombinant adenovirus vectors. Recently, we demonstrated that the HVJ-liposome method is useful for in vivo gene transfer to keratinocytes (20) and also that the introduction of the thymidine kinase gene to squamous cell carcinoma by this method, followed by administration of ganciclovir, resulted in inhibition of tumor growth (20). As each transfer method has both advantages and disadvantages, several alternative methods will have to be available for keratinocyte gene therapy in clinical practice depending on the situation.

Using the naked DNA injection method, the $\beta$-Gal gene was introduced and transiently expressed in pig and mouse keratinocytes, human skin organ cultures, and skin grafts (14). Furthermore, the IL- 8 gene was expressed in the keratinocytes after injection of its expression vector into the skin, and biological activity of IL-8 was found at the injection site (13). In terms of transfer efficacy, we compared the naked DNA method with the HVJ-liposome method and demonstrated that the former is five times more efficient than the latter (20). To achieve a high transfer efficacy, we used the naked DNA method in this study.

Several studies have asked whether the circulating gene product released from transduced keratinocytes could cause endocrine and systemic effects. Using ex vivo gene transfer methods, apolipoprotein E (8), human growth hormone (9), and human Factor IX (10) produced by transduced keratinocytes were reported to reach the bloodstream after keratinocyte transplantation. Sun et al. (4) transfected IL-6, TNF- $\alpha$, and IFN- $\gamma$ genes by particle-mediated gene transfer and detected IL- 6 and IFN- $\gamma$ in the skin and serum. Setoguchi et al. (7) detected $\alpha 1$-anti-trypsin in mouse serum after recombinant Ad $\alpha 1$ AT adenovirus vector transfer. Although these reports have shown the existence of transgene products in serum, sys- 
temic and endocrine effects of circulating transgene products have not been evaluated in case of transferring exogenous gene into keratinocytes using ex vivo and in vivo methods including the naked DNA transfer.

At first, IL-10 was isolated from T helper 2 cells which have an antiinflammatory function by inhibiting cytokine production by $\mathrm{T}$ helper 1 cells (24). Recent studies have shown that other kinds of cells including epidermal keratinocytes are capable of producing IL-10 $(25,26)$ and IL-10 has multiple effects including the prevention of autoimmune diabetes (27), inhibiting of tumor metastasis (28), and antiapoptotic activity (29). It is expected that IL-10 will be used in the treatment of many diseases in the future. In this study, we wondered whether IL-10, produced by gene-transferred keratinocytes, could enter the bloodstream and inhibit the effector phase of CHS at distant areas of the skin.

A recent study in our laboratory showed that a promoter/ enhancer cassette, which was constructed from a chicken modified $\beta$-actin promoter with the cytomegalovirus immediate early enhancer and the 3 -flanking sequence of the rabbit $\beta$-globin gene, strongly drove an encoding gene in keratinocytes in vivo (Sawamur, D., X. Meng, S. Ina, H. Nakano, K. Tamai, K. Nomura, K. Hanada, J. Miyazaki, Y. Ohe, and I. Hashimoto, manuscript submitted for publication). In this study, the expression vector phIL-10 was constructed using this promoter/enhancer cassette.

Since considerable amounts of IL-10 mRNA and protein were detected in phIL-10-treated keratinocytes, the dose of phIL-10 used for the injection was increased and the serum was assayed for human IL-10. Previous reports have demonstrated that intraperitoneal administration of rIL-10 inhibited the effector phase of CHS, but the serum levels of IL-10 were not discussed in detail. Cytokine concentration should normally be on the picomole level or above to have any biological effects. Assay of serum IL-10 showed that maximum concentrations were $\sim 1,8$, and 11 pmol after introduction of phIL-10 in doses of 80, 120, and $160 \mu \mathrm{g}$, respectively (Fig. 4). Gene transfer of 120 and $160 \mu \mathrm{g}$ of phIL-10 significantly inhibited the effector phase of CHS, whereas $80 \mu \mathrm{g}$ of phIL-10 did not (Fig. 5). These results reflect a relationship between the serum level of IL-10 and its inhibitory effect on CHS. On the other hand, although the half-life of IL-10 in vivo is $2 \mathrm{~h}(24,30)$, our results of serum IL-10 concentrations show that circulating IL10 can be kept for a relatively long time in phIL-10-injected rats in comparison to rats injected with rIL-10, and that serum IL-10 concentrations tended to increase with an increase in the amount of phIL-10 injected. Our results of IL-10 level in keratinocytes also demonstrated that the transgenic IL-10 can be kept at a higher level than subcutaneous injection of rIL-10. These results indicated that keratinocyte gene therapy should be more efficient for increasing cytokine concentration than direct injection of recombinant protein.

In this study, we have examined the systemic effects of a circulating gene product after introduction of the gene into keratinocytes using the subcutaneous naked DNA injection method. This system provides a potential way of treating diseases by using circulating gene products released from transduced keratinocytes. It is also applicable for understanding the systemic effects of other cytokines or hormones and to perform genetic immunization and vaccination. Furthermore, some inherited diseases such as hemophilia B may be cured by introduction of the human Factor IX gene into keratinocytes.
Currently, recombinant cytokines including interferon and interleukins, or recombinant hormones including insulin and growth hormones, are being used in clinical practice to treat patients with neoplastic, viral, inflammatory, and genetic disease. If a safe method could be developed to transfer therapeutic genes into keratinocytes much more efficiently and to maintain transgene expression for a long time, it may be possible to treat such patients with keratinocyte gene therapy in the future.

\section{Acknowledgments}

The authors would like to thank Prof. Akira Yasui (Institute of Development, Aging and Cancer, Tohoku University, Sendai, Japan) for providing the expression vector, pCY4B, and Dr. Yuhong Xiao for her guidance on animal experiments. We also thank Y. Uno and $\mathrm{K}$. Hanada for their excellent technical assistance.

\section{References}

1. Greenhalgh, D.A., J.A. Rothnagel, and D.R. Roop. 1994. Epidermis: an attractive target tissue for gene therapy. J. Invest. Dermatol. 103:63S-69S.

2. Fenjves, E.S. 1994. Approaches to gene transfer in keratinocytes. J. Invest. Dermatol. 103:70S-75S. 1483 .

3. Vogel, J.C. 1993. Keratinocyte gene therapy. Arch. Dermatol. 129:1478-

4. Sun, W.H., J.K. Burkholder, J. Sun, J. Culp, J. Turner, X.G. Lu, T.D. Pugh, W.B. Ershler, and N.S. Yang. 1995. In vivo cytokine gene transfer by gene gun reduces tumor growth in mice. Proc. Natl. Acad. Sci. USA. 92:28892893.

5. Tripathy, S.K., E. Goldwasser, M.M. Lu, E. Barr, and J.M. Leiden. 1994 Stable delivery of physiologic levels of recombinant erythopoietin to the systemic circulation of mice after intramuscular injection of replication-defective adenovirus. Proc. Natl. Acad. Sci. USA. 91:11557-11561.

6. Tripathy, S.K., E.C. Svensson, H.B. Black, E. Goldwasser, M. Margalith, P.M. Hobart, and J.M. Leiden. 1996. Long-term expression of erythopoietin in the systemic circulation of mice after intramuscular injection of a plasmid DNA vector. Proc. Natl. Acad. Sci. USA. 93:10876-10880.

7. Setoguchi, Y., H.A. Jaffe, C. Danel, and R.G. Crystal. 1994. Ex Vivo and in vivo gene transfer to the skin using replication-deficient recombinant adenovirus vectors. J. Invest. Dermatol. 102:415-421.

8. Fenjves, E.S., D.A. Gordon, L.K. Pershing, D.L. Williams, and L.B. Taichman. 1989. Systemic distribution of apolipoprotein E secreted by grafts of epidermal keratinocytes: implications for epidermal function and gene therapy. Proc. Natl. Acad. Sci. USA. 86:8803-8807.

9. Teumer, T., A. Lindahl, and H. Green. 1990. Human growth hormone in the blood of athymic mice grafted with cultures of hormone-secreting human keratinocytes. FASEB (Fed. Am. Soc. Exp. Biol.) J. 4:3245-3250.

10. Gerrard, A.J., D.L. Hudson, G.G. Brownlee, and F.M. Watt. 1993. Towards gene therapy for haemophilia B using primary human keratinocytes. Nat. Genet. 3:180-183.

11. Wolff, J.A., R.W. Malone, P. Williams, W. Chong, G. Acsadi, A. Jani, and P.L. Felgner. 1990. Direct gene transfer into mouse muscle in vivo. Science. 247:1465-1468.

12. Wolff, J.A., J.J. Ludtke, G. Acsadi, P. Williams, and A. Jani. 1992. Long-term persistence of plasmid DNA and foreign gene expression in mouse muscle. Hum. Mol. Genet. 1:363-369.

13. Hengge, U.R., E.F. Chan, R.A. Foster, P.S. Walker, and J.C. Vogel. 1995. Cytokine gene expression in epidermis with biological effects following injection of naked DNA. Nat. Genet. 10:161-166.

14. Hengge, U.R., P.S. Walker, and J.C. Vogel. 1996. Expression of naked DNA in human, pig, and mouse skin. J. Clin. Invest. 97:2911-2916.

15. Kondo, S., R.C. Mckenzie, and D.N. Sauder. 1994. Interleukin-10 inhibits the elicitation phase of allergic contact hypersensitivity. J. Invest. Dermatol. 103:811-814.

16. Schwarz, A., S. Grabbe, H. Riemann, Y. Aragane, M. Simon, S. Manon, S. Andrade, T.A. Luger, A. Zlotnik, and T. Schwarz. 1994. In vivo effects of interleukin-10 on contact hypersensitivity and delayed-type hypersensitivity reactions. J. Invest. Dermatol. 103:211-216.

17. Ferguson, T.A., P. Dube, and T.S. Griffith. 1994. Regulation of contact hypersensitivity by interleukin-10. J. Exp. Med. 179:1597-1604.

18. Berg, D.J., M.W. Leach, R. Kuhn, K. Rajewsky, W. Muller, N.J. Davidson, and D. Rennick. 1995. Interleukin 10 but not interleukin 4 is a natural suppressant of cutaneous inflammatory response. J. Exp. Med. 182:99-108.

19. Hanada, K., S. Chiyoya, K. Suzuki, I. Hashimoto, and I. Hatayama 1988. Study of the skin of a new hairless rat mutant. J. Dematol. 15:257-262. 
20. Sawamura, D., X.M. Meng, S. Ina, H. Ishikawa, K. Tamai, K. Nomura, K. Hanada, I. Hashimoto, and Y. Kaneda. 1997. In vivo transfer of a foreign gene to keratinocytes using the hemagglutinating virus of Japan-liposome methods. J. Invest. Dermatol. 108:195-199.

21. Vieira, P., R. de Waal-Malefyt, M.N. Dang, K.E. Johnson, R. Kastelein, D.F. Fiorentino, J.E. deVries, M.G. Roncarolo, T.R. Mosmann, and K.W. Moore. 1991. Isolation and expression of human cytokine synthesis inhibitory factor cDNA clones: homology to Epstein-Barr virus open reading frame BCRFI. Proc. Natl. Acad. Sci. USA. 88:1172-1176.

22. Nonoyama, S., M. Farrington, H. Ishida, M. Howard, and H. Ochs. 1993. Activated B cells from patients with common variable immunodeficiency proliferate and synthesize immunogloblin. J. Clin. Invest. 92:1282-1287.

23. Cheng, L., P.R. Ziegelhoffer, and N.S. Yang. 1993. In vivo promoter activity and transgene expression in mammalian somatic tissues evaluated by using particle bombardment. Proc. Natl. Acad. Sci. USA. 90:4455-4459.

24. Li, L., J.F. Elliott, and T.R. Mosmann. 1994. IL-10 inhibits cytokine production, vascular leakage, and swelling during $\mathrm{T}$ helper 1 cell-induced delayed type hypersensitivity. J. Immunol. 153:3967-3977.

25. Enk, A.H., and S.I. Katz. 1991. Identification and induction of kerati- nocyte-derived IL-10. J. Immunol. 149:92-95.

26. Grewe, M., K. Gyufko, and J. Krutmann. 1995. Interleukin-10 production by cultured human keratinocytes: regulation by ultraviolet B and ultraviolet A1 radiation. J. Invest. Dermatol. 104:3-6.

27. Moritani, M., K. Yoshomoto, S. Li, M. Kondo, H. Iwahara, T. Yamaoka, T. Sano, N. Nakano, H. Kikutani, and M. Itakura. 1996. Prevention of adoptively transferred diabetes in nonbese diabetic mice with IL-10-transduced isletspecific Th1 lymphocytes. A gene therapy model for autoimmune diabetes. $J$. Clin. Invest. 98:1851-1859.

28. Zheng, L.M., D.M. Ojcius, F. Garaud, C. Roth, E. Maxwell, Z. Li, H. Rong, J. Chen, X.Y. Wang, J.J. Catino, and I. King. 1996. Interleukin-10 inhibits tumor metastasis through an NK cell-dependent mechanism. J. Exp. Med. 184:579-584.

29. Kitabayashi, A., M. Hirokawa, and A.B. Miura. 1995. the role of interleukin-10 in chronic B-lymphocytic leukemia: IL-10 prevents leukemic cells from apoptotic cell death. Int. J. Hematol. 62:99-106.

30. Wanidworanun, C., and W. Strober. 1993. Predominant role of tumor necrosis factor- $\alpha$ in human monocyte IL-10 synthesis. J. Immunol. 151:68536861. 